\title{
Research on the Construction Path of "Chinese and Foreign Food Culture" Course from the Perspective of Cultural Confidence
}

\author{
Ren Daxin* \\ Shandong Technology and Business University \\ College of Management \\ Yantai, Shandong, China
}

\author{
Chen $\mathrm{Su}$ \\ Juancheng First Middle School \\ Heze, Shandong, China
}

\begin{abstract}
Cultural self-confidence is the firm affirmation and active practice of a nation, a country, and a political party for its own cultural values, and a firm confidence in the vitality of its culture. This article based on the perspective of "cultural selfconfidence", starting from the teaching and construction of the "Chinese and foreign food culture "course, comprehensively analyzedthe path of "Chinese and foreign food culture" curriculum.Under the perspective of implementation significance and cultural self-confidence, the construction strives to build a characteristic ideological and political course teaching model with demonstration leadership.
\end{abstract}

Keywords-cultural self-confidence; construction path; Chinese and foreign food culture

\section{INTRODUCTION}

The so-called cultural self-confidence is the recognition and pride of a country and a nation for its cultural values and its firm belief in cultural vitality. It is essentially an awakening of the cultural values. The report of the 19th National Congress of the Communist Party of China repeatedly emphasized the need to enhance cultural self-confidence, which shows that culture is the soul of a country and a nation. College students are the future builders and successors of China. They are an important force in inheriting and innovating Chinese culture. Their cultural value orientation and cultural behavior will affect the future cultural development of the Chinese nation. If the culture is prosperous, the country will flourish, and if the culture is powerful, the nation will be strong. Without a high degree of cultural selfconfidence or cultural prosperity, there would be no great rejuvenation of the Chinese nation.

"Chinese and foreign food culture" is a compulsory course for hotel management and tourism management, it mainly studies the fundamental theory, origin and development of Chinese and foreign catering culture, specific catering culture (such as food culture, wine culture, tea culture, etc.) and the exchange of Chinese and foreign catering culture. Through this course, students can provide better tourism and catering services by mastering the eating habits of different ethnic groups, different regions and different countries to meet the talent needs of the modern tourism hotel industry. Secondly, students can understand the systematic knowledge of Chinese food culture and can explore and analyze Chinese dietetic thoughts and phenomena. Finally, this course can also broaden students' horizons, improve students' comprehensive quality, improve their intercultural communication skills, and meet the requirements of today's international school. Through the explanation of traditional Chinese food culture, this course can enhance students' cultural self-confidence and cultural awareness, stimulate their motivation to actively learn Chinese culture, and lay a solid foundation for their employment and long-term development.

\section{THE SignifICANCE OF CURRICULUM CONSTRUCTION} AND IMPLEMENTATION FROM THE PERSPECTIVE OF CULTURAL SELF-CONFIDENCE

In theory, the analysis of curriculum construction and practice from the perspective of cultural self-confidence will provide new ideas and methods, which will help to tap the educational value of excellent traditional Chinese culture, enrich the theory of undergraduate education and the research of cultural self-confidence, and provide enlightenment for other courses, specialties and schools to carry out similar education.

In practice, traditional culture is the basis of national identity, and cultural self-confidence is the external manifestation of national identity. Through this research, it is beneficial to accumulate educational experience of this course, improve the curriculum education system, and provide experience for other courses, specialties and schools. It is helpful for teachers to correctly understand traditional culture education, improve corresponding knowledge structure and improve professional quality. It is helpful to stimulate students' sincere love for Chinese traditional culture, systematically learn relevant knowledge, improve their comprehensive quality, raise their moral character and cultivate good behavior habits, so as to gradually develop excellent moral character and perfect personality.

Therefore, in theory and in practice, curriculum construction has a positive meaning from the perspective of cultural self-confidence. 


\section{THE COURSE CONSTRUCTION PATH OF "CHINESE AND FOREIGN FOOD CULTURE" FROM THE PERSPECTIVE OF CULTURAL CONFIDENCE}

\section{A. Integrate and mine to form a teaching system}

Integrate the excellent materials that can be used to enhance students' humanities quality in traditional food culture, explore its contemporary value, form a set of targeted, feasible and focused teaching system, and clarify the logical relationship between traditional food culture and modern civilization. For example, cultivating students' patriotism and sense of social responsibility, guiding students to establish good eating habits, improve students' moral quality of cherishing food and so on. On this basis, students should acquire such cultural sentiments: "our food culture confidence comes not only from the cultural accumulation, inheritance, integration, innovation and development, but also from the development results and vitality of contemporary socialism with Chinese characteristics, and from shining practice and bright future of realizing the great rejuvenation of Chinese dream." Only in this way can we really cultivate students with strong comprehensive quality and self-confidence, who also have strong academic research ability, good moral character and a high sense of social responsibility.

\section{B. Conduct a comparative education on Chinese and foreign food culture to help students correctly understand the overseas food culture}

Through comparison, on the one hand, we can find the gap to improve ourselves; on the other hand, we can further strengthen our cultural confidence and consolidate the foundation of Chinese food culture. Under the background of comprehensive deepening reform, economic globalization and the Belt and Road Initiative, cultural exchanges and personnel exchanges between China and foreign countries will reach a new level. The college student group will be fully involved in the core layer of future high-level intellectuals. They are at the forefront, and a large influx of foreign culture, thoughts, and ways of thinking will have a huge impact on their group. If the perception of overseas culture is limited, it is easy to cause one-sided understanding, even cause blind worship, which has a negative impact on existing values and is not conducive to the improvement of humanistic quality. Therefore, in the perspective of firm cultural confidence, it is necessary to carry out comparative educate for Chinese contemporary college students, so they can correctly recognize overseas culture, improve their ability to distinguish essence and dross, and then become high-quality talents of new ear with self-confident and intercultural communication skills .

\section{Give play to the "practical value" of food culture and integrate into humanistic care}

In the process of cultivating the humanistic quality of college students, "humanistic care includes the dual concern for the survival and life value of human beings. It not only pays attention to the social existence value of human beings, but also the development of human dignity and spiritual health And this is not only a survival attitude and goal, but also a spiritual culture and social civilization appeal, which is a symbol of the healthy development of human nature and the progress of social civilization." To attach importance to humanistic care in the process of improving college students humanistic quality is not only a new requirement for college students' cultivation to adapt to the Pluralistic Background of the times and realize the Chinese Dream, but also a concrete action to implement the spirit of psychological counseling and humanistic care in the Eighteenth National Congress. As highend talents who shoulder the historical mission of national modernization and the great rejuvenation of the Chinese nation, college students will face more pressure and challenges, humanistic care is especially important. Humanistic care is helpful to cultivate rational, confident, optimistic and upward social mentality of college students, which not only takes care of the personality differences and personality display of college students, but also meets the needs of college students' spirit and psychology, and is of great benefit to selfimprovement and self-development of college students.

\section{Construction will integrate cultural self-confidence into} the normal mechanism of cultivating humanistic quality of college students, avoiding the flow of form and passing through

The normal mechanism can be built according to the professional characteristics of college students, aiming at improving humanistic spirit and highlighting social practice. The improvement of humanity quality including the accumulation of humanistic knowledge, humanistic thoughts and humanistic approaches and the cultivation of humanistic spirit and so on, especially the cultivation of humanistic spirit, needs a process of inner-turning. They must form their own thoughts and feelings through practice the theoretical knowledge into the external experience, so humanities knowledge can be transformed into humanistic spirit. The establishment of the normal mechanism can not only ensure the realization of this internalization process, but also expand the historical perspective and academic taste of college students, and greatly expand the cultivation space of humanistic quality. As the basis of humanistic quality education, Chinese traditional culture education is indispensable for college students. Under the influence of the extensive and profound traditional culture spirit, through the continuous accumulation of humanistic knowledge, college students can gradually transform the essence of traditional culture into their own character, form their own sense of responsibility and mission, so as to shape their good moral sentiment and patriotism.

\section{E. Improve the evaluation content and evaluation methods of college students' humanities quality, establish a systematic evaluation standard of humanities quality, and incorporate it into the evaluation system of college students}

The evaluation content of humanities quality can be flexible and diverse. For example, the achievements of various cultural and sports activities, art competitions, speech contests and various humanities and social science competitions that university students participate in can be counted. The evaluation method can be flexibly set according to the professional specialty of college students, or it can be carried 
out in the daily ideological and political education of college students. The evaluation methods should be multi-angled, multi-level and comprehensively constructed, and diversify to create an atmosphere of cultivation and promotion of humanistic quality. In a word, evaluation methods that can improve the humanities literacy of college students can be included in the undergraduate curriculum.

\section{THE CONSTRUCTION EFFECT OF "CHINESE AND FOREIGN FOOD CULTURE" CURRICULUM FROM THE PERSPECTIVE OF CULTURAL SELF-CONFIDENCE}

According to the above curriculum construction path, this course has carried out a multi-channel, all-round teaching reform. In order to test the effect and effectiveness of the reform, a questionnaire survey was set up.

\section{A. The object of the questionnaire}

"Chinese and foreign food culture" is a compulsory course for undergraduates of tourism management and hotel management in our school. Most of the courses are offered in the fourth or fifth semester. Therefore, there are 100 respondents in the questionnaire, and students of tourism management and hotel management are equally divided. In addition, the samples were classified in terms of gender and grade to avoid duplication.

\section{B. Questionnaire Setting and Analysis}

This questionnaire is conducted in a selective manner, but in order to avoid the one-sidedness of the question setting, the option of free answer is set under the part of the multiplechoice question. The questionnaire is divided into five parts. First, the personal characteristics of the respondents are counted, such as age, gender, major, and so on. Second, we investigated the cognition of this course. The survey was conducted in terms of course setting, class hours, lecture content, and homework. Again, we investigated the assessment methods of this course. For example, whether the assessment method is fair and notarized, whether the assessment content is comprehensive, whether the assessment time is reasonable and so on. And, the relationship between the effectiveness of the course and related courses is investigated, such as student's overall satisfaction with the course, the impact on future careers, and the links to related courses. Finally, we set up open topics, suggestions for this course, and so on.

The questionnaire is conducted in the form of "questionnaire stars". Through the establishment of Wechat Group to urge students to respond to questions and 100 questionnaires are effectively recovered. Through comparative analysis and telephone interview, all questionnaires are valid questionnaires, which can be included in the scope of results analysis. After all the questionnaires were collected through the network, the second, third and fourth parts of the questionnaire were mainly analyzed, and the data were analyzed and summarized by excel.

\section{Analysis of survey results}

Firstly, in the aspect of student sample selection, due to the corresponding regulations and settings on sample settings in advance, it is known that most students are 19 or 20 years old, a few students are 21 years old, and occasionally students are 22 years old, the ratio of male to female is $1: 3$ (the ratio of male students in both majors is low). Therefore, in order to improve the accuracy of the sample and the credibility of the research, optional coursed will be offered in the future to increase the total amount of samples and make the research more convincing.

Secondly, this part mainly investigates the respondents' perception of the course. In terms of curriculum, students in hotel management majors are more likely to engage in hotel management work in the future, and food culture is one of the key developments of the hotel, so most students have a higher awareness of this course, while students in tourism management have a slightly lower awareness of this course, and think that this course seems to be biased towards the training objectives of tourism management. They do not know that as an important "food" in the six elements of tourism, it is highly valued by tourists in nowadays society. "The food tour" has gradually moved into the public's vision. At the same time, it is also suggested that the recognized teachers should combine the actual situation of the industry in the future teaching, and combine with cases to teach in the teaching process. In terms of teaching content, this course is based on the fundamental theory (the relevant theory of Chinese food culture, the historical process of Chinese and western food culture, the difference and connection between Chinese and western food culture), and further modularized for specific chapters withdetailed introduction of specific food culture, such as Chinese and foreign wine culture, tea culture, food culture, tableware culture, banquet culture and dietary folklore on this basis, in order to achieve the goal of cultivating compound applied talents and cultivating students' intercultural communicative competence, we specially offer Chinese and foreign catering exchanges and extracurricular expert lectures, and invite American, Japanese and Korean teachers from our Foreign Languages Institute to give lectures.

In the theoretical part, the student response is more difficult to understand, suggesting that the instructor needs to explain the theoretical part in order to improve the teaching effect. In addition, it is also involved in the work, teaching methods and so on. However, in the follow-up interviews with juniors (completed this course and had interned in the hotel for half a year), most of the students responded that during the internship the knowledge gained in the classroom was applied and getting praise from guests by introducing Chinese traditional culture.

Thirdly, the assessment of the assessment method of this course abandons the traditional "final exam" or "finished homework" assessment method, and adopts a procedural, pluralistic and formative assessment method. For example, the introduction of usual performance grades. The usual class performance includes student attendance, class discussion, answering questions, class performance and so on. In this section, we mainly examine the process and effect of the 
students' basic classroom attendance, lectures and group discussions. The specific classroom attendance is in the form of irregular spot checks. The group discusses some of the questions raised during the teacher's explanation of the course and evaluates the results on the spot. Attendance is mainly conducted by the roll call, and class discussion, answering questions and class performance are determined by the teacher. In addition, a certain amount of extra points (usually around 2 points) is given to classmates who are actively performing in the classroom or classmates who offer constructive comments. Most of the students agree with this method, but some of them still disagree on the details, such as the calculation method of the usual scores, the evaluation criteria of group work, and so on. Therefore, in the future lectures, students should be explained in advance to understand the purpose of the establishment of similar evaluation criteria, specifically to examine the significance of the process settings, etc., in order to improve teaching effect.

Finally, the significance and suggestions of this course are discussed. Most of the students in this course believe that they have a positive effect on their future employment, but they don't know how to apply it. In view of this, teaching process should be more case-based in the future, such as how the 24 solar terms and dietary culture are related, how to promote the development of hotel catering industry and so on. In the aspect of students' free writing suggestions, some students put forward constructive suggestions on class hours, teaching contents, teaching methods, homework, etc. After seeing the suggestions, teachers held a student symposium and listened to students' opinions, which will be improved in the future teaching.

\section{CONCLUSION}

In the process of constructing the "Chinese and Foreign Diet Culture" course, in order to achieve a good teaching effect, this study carried out a specific construction plan for the course and conducted a questionnaire on the basis of which the teaching reform and suggestions for the specific teaching process were obtained, such as appropriate reform of teaching content, increase in teaching methods, and further meticulousness and improvement of the assessment process. In the future, we will further improve and enrich the teaching content to improve teaching effect, and promote this method to improve teaching achievements of similar majors.

Food culture is the spiritual treasure left by generations of generations.By giving it a new sense of time and generation, college students can aware their true cultural connotations and build cultural self-confidence. Only by understanding the Chinese story can we tell the story of China and send out the voice of China. In the process of promoting the development of China's new era, we can truly achieve the inheritance and development of Chinese food culture and establish a new era of cultural self-confidence.

\section{REFERENCES}

[1] Department of Higher Education, Ministry of Education. Notice of the Department of Higher Education of the Ministry of Education on the development of new engineering research and practice [2017] No. 6 [A/OL]. 2017-02-20,http: / /www.moe.edu.cn / s78 / A08 / A08 _ gggs / A08_sjhj/201702 / t20170223_297158. Html. (In Chinese)

[2] ZHAO Shu, "A Study on the Connotation of Chinese Tea Culture in College English Major Curriculum System from the Perspective of Cultural Confidence," Fujian Tea Research, Issue 11, pp. 361-362, Nov.2018. (In Chinese)

[3] TIAN Chaojie, "Exploration and practice of constructivist learning theory in the marketing teaching mode", Journal of Henan University of engineering ( Social Science Edition), Vol.32 No.2, pp. 84-86, Jun.2017. (In Chinese) 